\title{
Growth of Eremanthus erythropappus (DC.) MacLeish in Different Planting Spacings
}

\author{
Kalill José Viana da Páscoa ${ }^{1}$ (D), José Roberto Soares Scolforo ${ }^{1}$ (D), \\ Antonio Carlos Ferraz Filho ${ }^{1}$ (D), Thiza Falqueto Altoé ${ }^{\text {(D), }}$ \\ Lucas Rezende Gomide ${ }^{1}$ \\ ${ }^{1}$ Universidade Federal de Lavras - UFLA, Lavras/MG, Brasil
}

\begin{abstract}
This study aimed to evaluate the growth of Eremanthus erythropappus (DC.) MacLeish submitted to different planting spacing and growth modelling based on the diameter and crown area projection, as well as to identify the best management strategy to be applied to control the competition, period and intensity of thinning. The evaluated planting spacings were: $1.5 \times 1.5 \mathrm{~m} ; 1.5 \times 2.0 \mathrm{~m}$; $1.5 \times 2.5 \mathrm{~m}$ and $1.5 \times 3.0 \mathrm{~m}$. Diametric growth modelling in function of the age and crown area projection according to the mixed models methodology was efficient and the individual tree modelling allowed for defining a correct thinning prescription for tree plantations in relation to the percentage of removal needed at each spacing, thus permitting the trees to grow free from competition and produce trees with larger diameters.
\end{abstract}

Keywords: Individual tree models, forest management, thinning schedule. 


\section{INTRODUCTION}

Candeia (Eremanthus erythropappus (DC.) MacLeish) are one of the best-known forest species in the rural environment of Minas Gerais. Its wood is mainly used for producing fence posts due to its high resistance to termite and fungi attacks, and for the extraction of its essential oil. The main component of this oil is alpha-bisabolol, a natural terpene found in the formulation of several cosmetic and pharmaceutical products due to its anti-carcinogenic, anti-inflammatory, antibacterial, and antimycotic properties (Cerceau et al., 2016). The Brazilian production of alpha-bisabolol is almost totally destined to the external market (Santos et al., 2016), and natural stands of Candeia are the main source of this compound.

However, areas planted with Candeia have been increasing over the years, thus allowing exploitation of the species combined with its conservation in nature, thereby reducing the pressure on native remnants which are already over-exploited, and satisfying the market's appeal for products from planted forests, consequently maintaining the species' ability as a source of income (Scolforo et al., 2016a). The little existing knowledge about the silvicultural characteristics of the species is currently the great limiting factor for Candeia's commercial forestry production. Therefore, several studies have been developed to evaluate their growth when submitted to planting, seeking to generate recommendations that will contribute to the success of the crop. Among these studies we can point out Scolforo et al. (2016b), who evaluated the effect of different planting spacings on growth in young stands of Candeia, Scolforo et al. (2016a), who used statistical techniques based on spatial dependence to discriminate the fertilization treatments tested for the species. Both studies highlight the productive potential of these plantations as an alternative to more consecrated forest species, especially for the less productive areas in small rural properties.

According to this logic, the use of modeling leads to a complete diagnosis of the growth of forest species. Nutto (2001) reported that the crown (area) of a tree is closely related to its growth, since it is responsible for capturing sun energy and transforming it into chemical energy by the process of photosynthesis, and therefore the availability of light is a limiting factor to growth. According to this statement, crown diameter and crown area should be linearly correlated. Thus, the area available for crown expansion is a limiting factor for the individual growth, and may be a good indicator of the development potential of Candeia individuals. As a consequence, the allometric relationship between canopy area and tree diameter can be used as an indicator of the space required for a tree to reach its optimum growth without the effects of competition, allowing to verify whether the obtained products at the end of the rotation will present quality (in terms of dimensions) compatible with those obtained in exploiting native stands, or even indicating which silvicultural interferences are needed to achieve this goal.

Assmann (1970) defines that the competition between trees is more intense when canopy site coverage reaches the value of $78 \%\left(7.800 \mathrm{~m}^{2}\right.$ in 1 hectare $)$, and the canopies begin to overlap. This information can be used as an indication for the need of silvicultural interventions such as the creation of space due to the performance of thinning. In view of the above, the objective of this study is to use individual tree models to model the growth of Candeia trees based on the diameter and crown area projection, thereby seeking to define the management strategies in relation to the periods and intensity for thinning, so that trees with larger diameters can be produced by reducing the competition between individuals.

\section{MATERIAL AND METHODS}

\subsection{Study area and experimental design}

The experiment seeks to evaluate the effect of different plant spacing levels and pruning on the growth of Candeia trees. The experimental area was installed in the municipality of Carrancas, south of Minas Gerais, (UTM coordinates $529814.05 ; 7616938.17$ ) at an altitude of 1,035 meters, in a Cwa type climate (tropical altitude climate) according to the Köppen's classification system, with an average monthly temperature of $19.4^{\circ} \mathrm{C}$ and an average annual rainfall of $1,470 \mathrm{~mm}$. The soil is Displastic Haplic Cambisol, with a depth of more than $200 \mathrm{~cm}$. The contents of clay, silt and sand in the $0-20 \mathrm{~cm}$ layer are respectively 156,386 , and $459 \mathrm{~g} \cdot \mathrm{kg}^{-1}$.

The experiment followed a randomized complete block design scheme subdivided by time, with four blocks and two sources of variation: the planting spacing 
(T1: $1.5 \times 1.5 \mathrm{~m}, \mathrm{~T} 2: 1.5 \times 2.0 \mathrm{~m}, \mathrm{~T} 3: 1.5 \times 2.5 \mathrm{~m}$, and T4: $1.5 \times 3.0 \mathrm{~m}$ ) and the application, or not, of artificial pruning (Figure 1). Pruning was performed with the objective of producing single tree trunks with potential use for producing fence posts. It was carried out at $0.67,2.67$ and 6.58 years and consisted in removing branches from the base of the canopy, respecting the portion of canopy removed equal to or less than $45 \%$, and the maximum height of $1 / 3$ the total height. A total of 224 trees were planted in each plot; of this total, 112 trees were pruned and 112 used as controls. The database was comprised of periodic measurements carried out at intervals of 6 to 12 months by the (stem) diameter measured at $1.30 \mathrm{~m}$ from the soil (DBH), total height (HT), and crown projection area (CA), totaling 16 measurements over 10.25 years.

\subsection{Analysis of treatment effects}

The effect of spacings and pruning on the dendrometric variables was analyzed using the variance analysis technique. For the cases where there was a significant difference according to the F-test between the sources of variation or between their iterations, the appropriate procedure for comparing the means was performed. Regression analysis was performed for the quantitative factors of Spacing and Age, and the Scott Knott mean test with 5\% significance was applied for the qualitative factor of Pruning; however, as it presents only 1 degree of freedom (with or without pruning), the simple finding of significance by the F-test already indicated that the highest mean was different from the lowest.

\subsection{Growth modeling}

Due to the hierarchical structure of the data (repeated measures over the years submitted to different treatments), mixed effects models were adjusted for both diametric growth as a function of age and growth projection of the crown area as a function of the diametric growth using the maximum likelihood procedure through the nlme and lme packages of $\mathrm{R}$ software (R Development Core Team, 2015).

The Maximum Likelihood Logarithm value (Log Lik), the Akaike Information Criterion (AIC), and the Bayesian Information Criterion (BIC) were used for comparison and for selecting the most

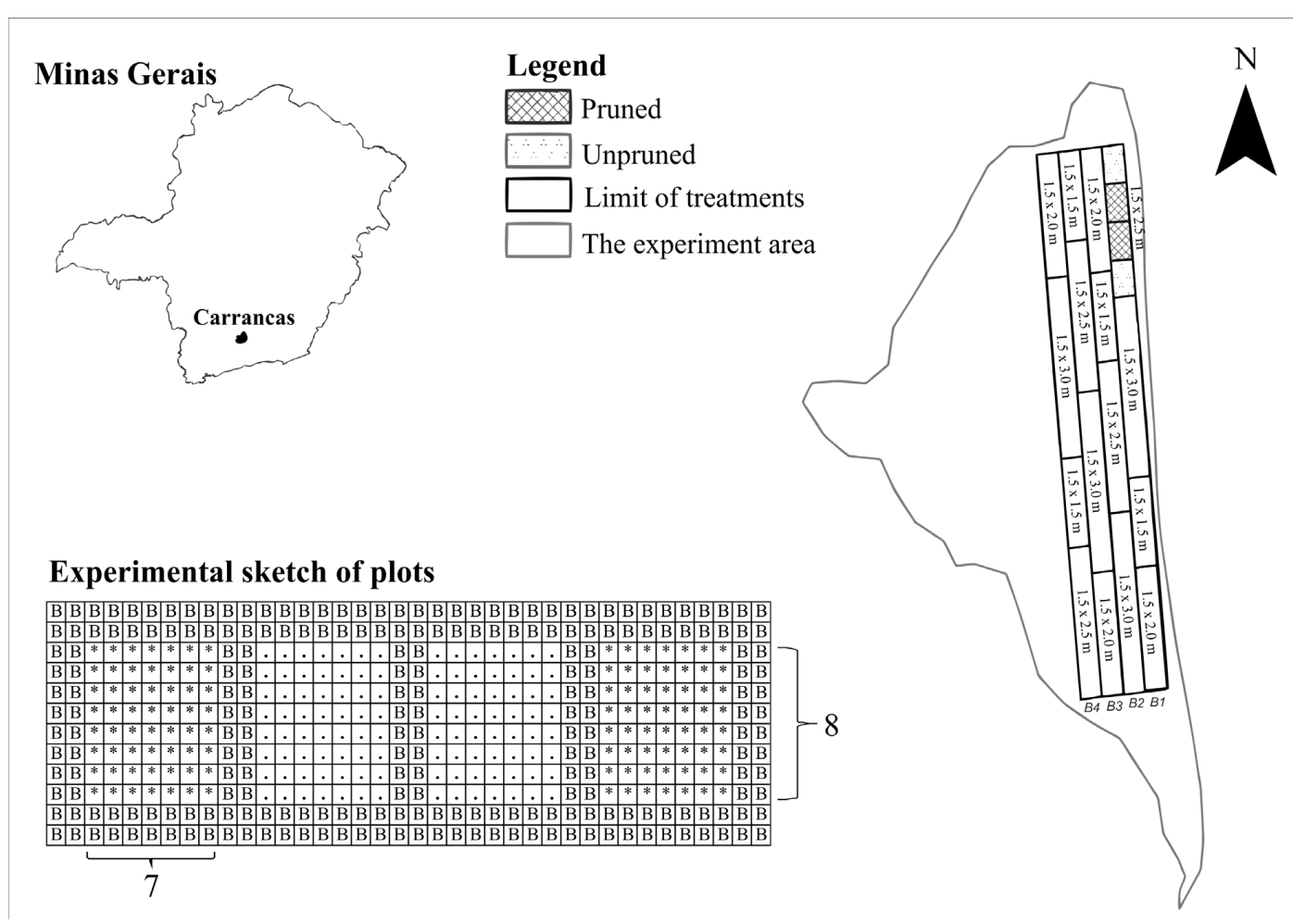

Figure 1. Experimental design of the study area. 
appropriate model for analysis. Diametric growth modeling according to age used the Chapman and Richards growth model, Equation 1:

$D B H=\beta_{0} *\left(1-e^{\beta_{1}^{*} \mathrm{Id}}\right)^{\beta_{2}}+\varepsilon_{i}$

Where: $\mathrm{DBH}$ is the diameter at the age Id; $\beta_{0}$ is the asymptotic value that the tree can reach; $\beta_{1}$ is the relative measure of the growth rate; Id is the age at which you want to estimate; $\beta_{2}$ expresses the curve shape.

The growth modeling of the CA was subsequently performed according to the DBH. For this adjustment, the Kopezky-Gehrardt model was used, Equation 2:

$$
C A=\beta_{0}+\beta_{1} D B H^{2}+\varepsilon_{i}
$$

In which: CA is the canopy area; $\mathrm{DBH}$ is the diameter measured at $1.30 \mathrm{~m}$ from the ground.

\subsection{Definition of tree density per hectare}

DBH estimates according to age were used to estimate the crown projection area at the various ages, enabling knowledge of the site occupation by the canopy for each of the tested spacings over the years. The need for intervention was evaluated for each year using canopy occupancy greater than $78 \%$ as a restriction. In the cases where the coverage was higher, the number of trees to be removed per hectare was determined in order to maintain the occupation below this threshold, allowing to achieve an economic rotation for Candeia plantations (Scolforo et al., 2016b), the final density of plants at the end of rotation, the percentage of plants to be removed, and the best schedule for thinning application after 15 years.

\section{RESULTS AND DISCUSSION}

\subsection{Analysis of the treatment effects}

Table 1 shows the mean values for the DBH, HT and CA variables at 10.25 years, in addition to their standard deviation (SD) and the number of individuals per plot (n) for the evaluated treatments in relation to the plant spacings and pruning applications. It can be observed that the $n$ values refer to mortality, indicating that it was higher in smaller spacings, while the standard deviation indicates that HT values are much more homogeneous among treatments than those found for $\mathrm{DBH}$ and $\mathrm{CA}$.

The analysis of variance (Table 2) showed a significant effect of spacing and pruning at a significance level of $5 \%$ on the variables $\mathrm{DBH}$ and $\mathrm{CA}$, indicating that the means of these variables tend to increase linearly with the increase in spacing due to the greater availability of living space for each plant, and consequently less competition.

The interaction between spacing and pruning was only significant for CA. As expected, age had a highly significant effect for all variables. Its interaction with the spacing factor was significant for $\mathrm{DBH}$ and $\mathrm{CA}$, while the interaction of age with pruning was significant for DBH and HT. Finally, the triple interaction (spacing, pruning and age) was not significant for any of the analyzed variables.

The unfolding of the interaction between spacing and age for the $\mathrm{DBH}$ variable indicates that the differences between the diameters according to the different spacings intensified over the years, especially

Table 1. Means and standard deviation for the variables DBH, HT and CA in relation to the spacings and pruning of Candeia.

\begin{tabular}{|lcccccccc}
\multicolumn{2}{c}{ Treatment } & $\mathbf{n}$ & $\mathbf{D B H}_{\text {mean }}$ & $\mathbf{S D}_{\mathrm{DBH}}$ & $\mathbf{H T}_{\text {mean }}$ & $\mathbf{S D}_{\mathrm{HT}}$ & $\mathbf{C A}_{\text {mean }}$ & $\mathbf{S D}_{\mathrm{CA}}$ \\
\hline $1.5 \times 1.5 \mathrm{~m}$ & Without pruning & 164 & 6.5 & 1.94 & 5.1 & 0.56 & 2.6 & 1.66 \\
$1.5 \times 1.5 \mathrm{~m}$ & With pruning & 143 & 7.2 & 1.99 & 5.3 & 0.61 & 2.5 & 1.65 \\
\hline $1.5 \times 2.0 \mathrm{~m}$ & Without pruning & 160 & 7.6 & 2.35 & 5.3 & 0.57 & 3.0 & 1.82 \\
$1.5 \times 2.0 \mathrm{~m}$ & With pruning & 130 & 7.7 & 2.56 & 5.3 & 0.73 & 3.2 & 1.87 \\
\hline $1.5 \times 2.5 \mathrm{~m}$ & Without pruning & 177 & 7.9 & 2.49 & 5.1 & 0.60 & 4.0 & 2.31 \\
$1.5 \times 2,5 \mathrm{~m}$ & With pruning & 171 & 8.1 & 2.33 & 5.3 & 0.66 & 3.6 & 1.91 \\
\hline $1.5 \times 3.0 \mathrm{~m}$ & Without pruning & 176 & 8.6 & 2.32 & 5.2 & 0.53 & 4.7 & 2.49 \\
$1.5 \times 3.0 \mathrm{~m}$ & With pruning & 177 & 8.4 & 2.41 & 5.1 & 0.59 & 3.9 & 1.88 \\
\hline
\end{tabular}

$\mathrm{n}$ : number of trees; $\mathrm{DBH}_{\text {man }}=$ mean of diameter at breast height $(\mathrm{cm}) ; \mathrm{SD}_{\mathrm{DBH}}=$ standard deviation of diameter at breast height $\left(\mathrm{cm}^{2}\right)$ $\mathrm{HT}_{\text {mean }}=$ mean of total height $(\mathrm{m}) ; \mathrm{SD}_{\mathrm{HT}}=$ standard deviation of total height $\left(\mathrm{m}^{2}\right) ; \mathrm{CA}_{\text {mean }}=$ mean of crown area $\left(\mathrm{m}^{2}\right) ; \mathrm{SD}_{\mathrm{CA}}=$ standard deviation of crown area $\left(\mathrm{m}^{4}\right)$. 
Table 2. Summary of the analysis of variance for the values of the dendrometric variables DBH, HT, and CA in relation to spacings, pruning and age for Candeia.

\begin{tabular}{|cccccc|}
\hline Source of variation & DF & \multicolumn{3}{c|}{ MS } \\
\cline { 3 - 6 } Spacing & & DBH & HT & CA \\
\hline Block & 3 & $13.6^{*}$ & 0.08 & $13.39^{*}$ \\
\hline Error 1 & 3 & 0.79 & 0.59 & 0.24 \\
\hline Pruning & 9 & 1.68 & 0.3 & 0.57 \\
\hline Spacing $\times$ Pruning & 1 & $11.02^{*}$ & 0.94 & $7.74^{*}$ \\
\hline Error 2 & 3 & 2.14 & 0.41 & $1.19^{*}$ \\
\hline Age & 12 & 1.45 & 0.22 & 0.27 \\
\hline Age $\times$ Spacing & $15(6)$ & $175.46^{*}$ & $59.99^{*}$ & $8.49^{*}$ \\
\hline Age $\times$ Pruning & $45(8)$ & $0.59^{*}$ & 0.01 & $0.31^{*}$ \\
\hline Age $\times$ Spacing $\times$ Pruning & $15(6)$ & $0.43^{*}$ & $0.04^{*}$ & 0.25 \\
\hline Error 3 & $45(18)$ & 0.09 & 0.01 & 0.05 \\
\hline Corrected total & $360(144)$ & 0.12 & 0.02 & 0.14 \\
\hline
\end{tabular}

The degrees of freedom (DF) values in parentheses refer to the CA variable, which differ from the others due to a smaller number of measurements ( 7 measurements); MS = mean square; * significance at a $5 \%$ probability level; DBH= diameter at breast height, $\mathrm{HT}=$ total height, $\mathrm{CA}=$ crown area.

after 4.17 years, indicating the effect of competition. On the other hand, the interaction between pruning and age indicates that the differences between $\mathrm{DBH}$ were significant between the ages 3.75 and 8.91 years, with treatments that had received pruning presenting higher values.

Mean DBH values for Candeia at 10.25 years ranged from $6.0 \mathrm{~cm}$ in the smallest spacing and $8.0 \mathrm{~cm}$ in the largest spacing, with a coefficient of variation $(\mathrm{CV})$ of $29 \%$. In turn the treatments which underwent pruning presented $\mathrm{DBH}$ values around 3\% higher than those which did not undergo pruning; this is probably a response to the removal of branches that contribute little in producing photoassimilates, concentrating the growth in a single branch/shaft. Comparing these results with those presented in the literature for Candeia in native forest, Pérez et al. (2004) determined (by stem analysis) that trees belonging to the diameter class of $5-10 \mathrm{~cm}$ (which corresponds to the mean values found in the present study) are on average 18 years of age. On the other hand, analyzing two Candeia stands with a mean $\mathrm{DBH}$ of 6.8 and $6.9 \mathrm{~cm}$, Mori et al. (2009) found ages of 34 and 24, respectively. These results demonstrate the development potential of planted Candeia, since its $\mathrm{DBH}$ at 10.25 years is similar to that of native trees aged between 18 and 34 years.

Unlike the DBH, no differences were observed between plant spacings and growth height for Candeia; however, a slight increase in mean heights was noticed with the application of artificial pruning. In relation to the canopy area, an increase in this variable in relation to the increase of the planting spacing was noticed; a logical response by the trees to the greater availability of useful area for canopy expansion, which as a consequence is responsible for greater light interception and photoassimilate production, leading trees with larger spacings to achieve greater mean DBHs.

\subsection{Diametric growth modeling}

For adjustment of the Chapman and Richards model, all parameters were initially considered as random components to capture the variability between the individuals submitted to each of the treatments. Then the random effect parameters were removed one by one until all possible combinations had been made.

Table 3 shows the adjusted combinations along with which parameters had their effects considered random for each of the 7 models, and the statistics used for the comparison: Akaike Information Criterion (AIC), Bayesian Information Criterion (BIC), and Maximum Likelihood Logarithm (Log Lik).

According to the statistics the chosen model was model 2, which considered the random effects on parameters $\beta_{1}$ and $\beta_{2}$, since it presented the lowest AIC (183501.3) and BIC values (183563.0), and the highest Lik Log value (-91743.66), with a standard 
estimate error (Syx) value of $1.55 \mathrm{~cm}$. Thus, it can be stated that the treatments had an effect on the scale parameter $\left(\beta_{1}\right)$, which is closely related to the growth rate of trees and to the parameter related to inflexion $\left(\beta_{2}\right)$, which is the parameter that reflects the curve shape and marks a change in the growth phase of the plants. The values for $\beta_{0}, \beta_{1}$ and $\beta_{2}$ parameters for each treatment are presented in Table 4 , and all were statistically significant ( $\mathrm{p}$-value $<0.05$ ). The $\beta_{0}$ values are the same among all treatments since its effect was considered fixed.

According to Scolforo (2006), the $\beta_{2}$ value tends to be smaller at higher densities, indicating that the inflection point occurs very early, while the $\beta_{1}$ value tends to be greater at lower densities, since individuals typically reach larger dimensions. According to Cropper \& Putz (2017), the mixed effects models perform substantially better when compared to the fixed effects approach, and studies on the effect of different silvicultural treatments allow the insertion of these effects into the model construction, improving the explanatory power of growth.

\subsection{Modeling the canopy projection area}

The same methodology described above was followed for the growth modeling of the crown projection area using the Kopezky-Gehrardt model. Table 5 shows which parameters had their effects considered random for each of the 3 models, in addition to the statistics used for comparisons.

According to the statistics presented previously, the chosen model was model 1 , which considered all parameters as random effects, with lower ICA (60771.85) and BIC values (60819.5), and the highest $\log$ Lik values (-30379.93). The value of the estimated standard error for the selected model was $1.04 \mathrm{~m}^{2}$. Therefore, it can be stated that the treatments had an effect on the values of the intercept $\left(\beta_{0}\right)$ and scale $\left(\beta_{1}\right)$ parameters, which are closely related to the trees' growth rate. The values of the parameters $\beta_{0}$ and $\beta_{1}$ for each treatment are presented in Table 6, and all were considered statistically significant ( $\mathrm{p}$-value $<0.05$ ).

By observing the $\beta_{1}$ value it is possible to notice that it tends to be greater at lower densities, indicating that the inclination of the model is greater, and the individuals consequently present larger dimensions.

Table 3. Summary of the comparison statistics for Chapman-Richards models adjusted by the methodology of mixed models for the DBH growth for Candeia according to age.

\begin{tabular}{cccccc} 
Model & DF & Random effect & AIC & BIC & Log Lik \\
\hline 1 & 10 & $\beta_{0}$. $\beta_{1}$ e $\beta_{2}$ & 183507.3 & 183595.4 & -91743.66 \\
2 & 7 & $\beta_{1}$ e $\beta_{2}$ & 183501.3 & 183563.0 & -91743.66 \\
3 & 5 & $\beta_{2}$ & 184890.6 & 184934.6 & -92440.28 \\
4 & 5 & $\beta_{1}$ & 183998.9 & 184042.9 & -91994.45 \\
\hline 5 & 5 & $\beta_{0}$ & 183647.0 & 183691.0 & -91818.47 \\
6 & 7 & $\beta_{0} \mathrm{e} \beta_{1}$ & 183565.1 & 183626.8 & -91775.56 \\
\hline 7 & 7 & $\beta_{0} \mathrm{e} \beta_{2}$ & 183540.4 & 183602.1 & -91763.21 \\
\hline
\end{tabular}

$\mathrm{AIC}=$ Akaike Information Criterion; BIC $=$ Bayesian information criterion; Log Lik $=$ Maximum Likelihood Logarithm.

Table 4. Values of the parameters $\beta_{0}, \beta_{1}$, and $\beta_{2}$ for each treatment of the model selected by the methodology of mixed models for $\mathrm{DBH}$ growth as a function of age for Candeia.

\begin{tabular}{|lcccc}
\multicolumn{2}{c}{ Treatment } & $\boldsymbol{\beta}_{\mathbf{0}}$ & $\boldsymbol{\beta}_{\mathbf{1}}$ & $\boldsymbol{\beta}_{\mathbf{2}}$ \\
\hline $1.5 \times 1.5 \mathrm{~m}$ & Without pruning & 9.242994 & -0.1072991 & 0.9665149 \\
$1.5 \times 1.5 \mathrm{~m}$ & With pruning & 9.242994 & -0.1659229 & 1.1883525 \\
$1.5 \times 2.0 \mathrm{~m}$ & Without pruning & 9.242994 & -0.1874871 & 1.3272517 \\
$1.5 \times 2.0 \mathrm{~m}$ & With pruning & 9.242994 & -0.2124146 & 1.4389406 \\
$1.5 \times 2.5 \mathrm{~m}$ & Without pruning & 9.242994 & -0.2023390 & 1.4391196 \\
$1.5 \times 2.5 \mathrm{~m}$ & With pruning & 9.242994 & -0.2449166 & 1.5936103 \\
$1.5 \times 3.0 \mathrm{~m}$ & Without pruning & 9.242994 & -0.2675539 & 1.7566610 \\
\hline $1.5 \times 3.0 \mathrm{~m}$ & With pruning & 9.242994 & -0.2649459 & 1.7241284 \\
\hline
\end{tabular}


Table 5. Summary statistics for model comparisons adjusted with mixed model methodology for the growth of CA as a function of DBH.

\begin{tabular}{cccccc} 
Model & DF & Random effect & AIC & BIC & Log Lik \\
\hline 1 & 6 & $\beta_{0}$ and $\beta_{1}$ & 60771.85 & 60819.5 & -30379.93 \\
2 & 4 & $\beta_{0}$ & 60841.58 & 60873.34 & -30416.79 \\
3 & 4 & $\beta_{1}$ & 61731.63 & 61763.4 & -30861.82 \\
\hline
\end{tabular}

$\mathrm{DF}=$ degrees of freedom; AIC = Akaike Information Criterion; BIC = Bayesian information criterion; Log Lik = Maximum Likelihood Logarithm.

Table 6. Values of the parameters $\beta_{0}$ and $\beta_{1}$ for each treatment of the model selected by the methodology of mixed models for CA growth as a function of DBH.

\begin{tabular}{lccc}
\multicolumn{2}{c}{ Treatment } & $\boldsymbol{\beta}_{\mathbf{0}}$ & $\boldsymbol{\beta}_{1}$ \\
$1.5 \times 1.5 \mathrm{~m}$ & Without pruning & 1.2122820 & 0.03315637 \\
$1.5 \times 1.5 \mathrm{~m}$ & With pruning & 0.9411892 & 0.02970979 \\
$1.5 \times 2.0 \mathrm{~m}$ & Without pruning & 1.6097919 & 0.02474258 \\
$1.5 \times 2.0 \mathrm{~m}$ & With pruning & 1.1481956 & 0.02932045 \\
$1.5 \times 2.5 \mathrm{~m}$ & Without pruning & 1.8604802 & 0.03014336 \\
$1.5 \times 2.5 \mathrm{~m}$ & With pruning & 1.2035727 & 0.03177627 \\
$1.5 \times 3.0 \mathrm{~m}$ & Without pruning & 2.0715486 & 0.03124670 \\
$1.5 \times 3.0 \mathrm{~m}$ & With pruning & 1.3699359 & 0.03140604 \\
\hline
\end{tabular}

\subsection{Management based on individual trees}

Once the hypothesis that DBH is linearly correlated with the CA is confirmed, it can be affirmed that planting spacing represents a limiting factor to individual tree growth due to the obstacle related to canopy development, considering that it is necessary that the trees grow free of competition for canopies to reach their potential size. Thus, using the individual previously calculated estimates, the occupation of the site by the canopies for each treatment was evaluated. Figure 2 shows the maximum number of plants supported by each site over the years in order for trees to grow free of competition (sum of the areas of individual crowns is less than or equal to $7.800 \mathrm{~m}^{2}$ in 1 hectare), in addition to estimated mean values for the crown projection area.

It can be noted that it was necessary to decrease the initial planting density at the end of the rotation for all evaluated treatments. Greater planting spacings are able to reach higher values of CA, from which the required removal rate is considerably lower due to the greater available space per plant. Based on these results, it is possible to prescribe recommendations for thinning applications to manage Candeia forests.
In relation to the number of trees supported at the end of rotation, these values are presented in Table 7 along with the initial density for each treatment, the percentage of removal required and the mean $\mathrm{DBH}$ at the thinning application age, and the mean DBH at the end of the rotation, with the benefits resulting from the reduced competition.

The thinning plan to be performed consists of applying the sum of the required removal throughout the rotation in the first year, where the occupancy value exceeded $78 \%$. The occupancy rate for the $1.5 \times 1.5 \mathrm{~m}$ spacing without pruning was exceeded at 6 years, so that only 2622 plants/ha would be supported at the end of the rotation, meaning that $41 \%$ should be removed by thinning. In the same spacing with pruning application, it was evidenced that the maximum value of occupation was reached at 5 years, and the required removal percentage was $46 \%$. In these two treatments the required thinning is severe, and the removal of approximately half of the initial planting density would compromise the economic feasibility of the planting, considering that even with pruning application, the average $\mathrm{DBH}$ values reached at the end of the rotation would be small ( 7.3 and $8.8 \mathrm{~cm}$, respectively).

The maximum value of occupation for the $1.5 \times 2.0 \mathrm{~m}$ spacing both without and with pruning application was reached at 4 years. It would be necessary to remove $35 \%$ of the initially planted individuals at the end of the rotation, and the DBH values reached would be 9.0 and $9.2 \mathrm{~cm}$, respectively. For the $1.5 \times 2.5 \mathrm{~m}$ spacing without pruning, the maximum value of occupancy was exceeded after 4 years, requiring the removal of $33 \%$ of the individuals. With pruning application, the maximum occupancy value was reached at only 5 years, and the thinning removal intensity was $25 \%$. 

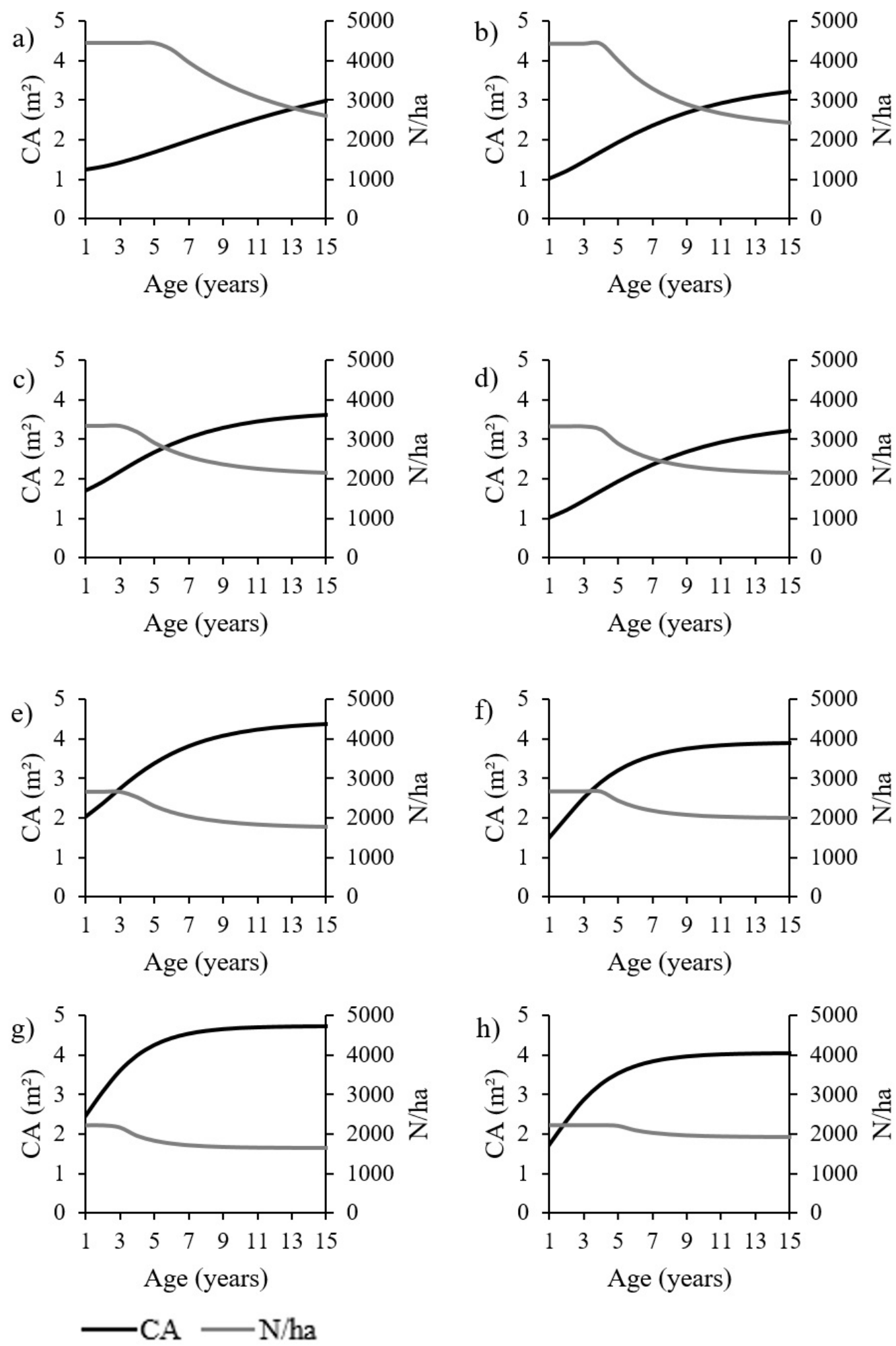

Figure 2. Estimated values of CA for Candeia with the number of plants supported per ectare in each treatment: a) $1.5 \times 1.5 \mathrm{~m}$ without pruning; b) $1.5 \times 1.5 \mathrm{~m}$ with pruning; c) $1.5 \times 2.0 \mathrm{~m}$ without pruning; d) $1.5 \times 2.0 \mathrm{~m}$ with pruning; e) $1.5 \times 2.5 \mathrm{~m}$ without pruning; f) $1.5 \times 2.5 \mathrm{~m}$ with pruning; g) $1.5 \times 3.0 \mathrm{~m}$ without pruning; h) $1.5 \times 3.0 \mathrm{~m}$ with pruning. 
Table 7. Initial density of individuals per hectare, age at thinning application, number of individuals removed, percentage of removal, and final density per hectare for evaluated treatments for Candeia.

\begin{tabular}{lcccccc} 
Treatment & $\begin{array}{c}\text { Initial N } \\
\text { (N/ha) }\end{array}$ & $\begin{array}{c}\mathbf{I}_{\text {thinning }} \\
\text { (years) }\end{array}$ & $\begin{array}{c}\mathbf{D B H}_{\text {thinning }} \\
(\mathbf{c m})\end{array}$ & $\begin{array}{c}\text { Removal } \\
(\%)\end{array}$ & $\begin{array}{c}\mathbf{D B H}_{\text {final }} \\
(\mathbf{c m})\end{array}$ \\
\hline $1.5 \times 1.5 \mathrm{~m}$ & Without pruning & 4444 & 6 & 4.3 & $41 \%$ & 7.3 \\
$1.5 \times 1.5 \mathrm{~m}$ & With pruning & 4444 & 5 & 5.8 & $46 \%$ & 8.8 \\
$1.5 \times 2.0 \mathrm{~m}$ & Without pruning & 3333 & 4 & 5.8 & $35 \%$ & 9.0 \\
$1.5 \times 2.0 \mathrm{~m}$ & With pruning & 3333 & 4 & 6.5 & $35 \%$ & 9.2 \\
$1.5 \times 2.5 \mathrm{~m}$ & Without pruning & 2667 & 4 & 6.4 & $33 \%$ & 9.2 \\
$1.5 \times 2.5 \mathrm{~m}$ & With pruning & 2667 & 5 & 7.9 & $25 \%$ & 9.2 \\
$1.5 \times 3.0 \mathrm{~m}$ & Without pruning & 2222 & 3 & 7.0 & $23 \%$ & 9.2 \\
$1.5 \times 3.0 \mathrm{~m}$ & With pruning & 2222 & 5 & 8.3 & $13 \%$ & 9.2 \\
\hline
\end{tabular}

Initial = Initial density of individuals per hectare; $\mathrm{N}=$ age at thinning application (years); $\mathrm{DBH}_{\text {thinning }}=$ mean of the diameters at the moment of thinning application $(\mathrm{cm})$; Removal = percentage of individuals removal in relation to the initial density; $\mathrm{DBH}_{\text {final }}=$ mean of the diameters after the application of the thinning $(\mathrm{cm})$.

The mean DBH values reached would be $9.2 \mathrm{~cm}$ for both treatments.

In relation to the $1.5 \times 3.0 \mathrm{~m}$ spacing without pruning, the maximum occupancy value was reached at 3 years and the required removal intensity was $23 \%$. With pruning application the occupation was reached at 5 years, two years after the same spacing without pruning, and the pruning application would require the removal of only $13 \%$ of the plants, while the mean DBH would be $9.2 \mathrm{~cm}$ in both treatments.

Smaller planting spacings require that a large amount of trees be removed over time, since the planting density is very high. It can be noted that the growth rate in these spacings is also lower, since the occupation value for the $1.5 \times 1.5 \mathrm{~m}$ spacing was only exceeded at 5 and 6 years (respectively with and without pruning), even presenting a lower available area by plant. Due to these characteristics, very reduced planting spacings should not be recommended for Candeia, since the producer would invest a significant amount of money in buying and planting the seedlings, and most of them would be cut out in the future with a low $\mathrm{DBH}$.

In relation to the other spacings, all produced trees with similar dimensions at the end of rotation, but the main difference was the use of pruned trees. In the $1.5 \times 2.0 \mathrm{~m}$ spacing (with and without pruning) and in the $1.5 \times 2.5 \mathrm{~m}$ spacing without pruning, the removal of trees by thinning does not allow them to reach the specified size for them to be used as fence posts, and they are also not suitable for oil extraction because trees with small diameters do not produce much oil, thus configuring non-commercial thinning.
In order to produce trees with higher dimensions to be marketed as fence posts or for the extraction of large quantities of oil, lower initial planting densities are indicated such as those achieved with $1.5 \times 2.5 \mathrm{~m}$ and $1.5 \times 3.0 \mathrm{~m}$ spacings with pruning. In addition to these treatments not requiring the removal of a large number of trees, the final dimension of the stems allow to obtain a good profit; results which corroborate those found by Scolforo et al. (2016b).

Therefore, what does justify pruning application, despite it removing part of the crown, is the increase in the efficiency of the crown by the removal of basal branches shaded by others, which contribute very little or nothing to photosynthesis. Another point that justifies application of thinning in planted Candeia stands is the high genetic variability among the plants; thus, trees with better phenotypes could be selected to remain, while worse ones could be removed in the thinning.

\section{CONCLUSION}

The hypothesis that DBH is linearly correlated with $\mathrm{CA}$ and that the planting spacing can limit individual tree growth due to being an obstacle for crown development was proven. The evaluation of the canopy occupation for each spacing allowed a recommendation of thinning prescriptions, in which the removal rate of individuals in relation to initial planting density varied between $13 \%$ and $41 \%$, respectively, for the $1.5 \times 3.0 \mathrm{~m}$ and the $1.5 \times 1.5 \mathrm{~m}$ spacings, and the age of the thinning application varied between 3 and 6 years for the same spacings. The optimal moment for applying pruning is 
between 2 and 3 years. Therefore, in order to produce trees with higher dimensions to be commercialized as fence posts or for the extraction of large quantities of oil, lower initial planting densities are indicated such as the $1.5 \times 2.5 \mathrm{~m}$ spacing and $1.5 \times 3.0 \mathrm{~m}$ spacing with pruning application.

\section{ACKNOWLEDGEMENTS}

The Foundation for Research Support of the State of Minas Gerais (FAPEMIG) for providing financial support.

\section{SUBMISSION STATUS}

Received: 4 aug., 2017

Accepted: 27 mar., 2018

\section{CORRESPONDENCE TO}

\section{Kalill José Viana da Páscoa}

Departamento, Universidade Federal de Lavras

- UFLA, Câmpus Universitário, s/n, CP 3037,

CEP 37200-000, Lavras, MG, Brasil

e-mail: kalillpascoa@gmail.com

\section{REFERENCES}

Assmann E. The principles of forest yield study. Oxford: Pergamon Press; 1970.

Cerceau CI, Barbosa LC, Alvarenga ES, Ferreira AG, Thomasi SS. A validated $1 \mathrm{H}$ NMR method for quantitative analysis of a-bisabolol in essential oils of Eremanthus erythropappus. Talanta 2016; 161: 71-79. http://dx.doi. org/10.1016/j.talanta.2016.08.032. PMid:27769470.

Cropper WP, Putz FE. Tree diameter increments following silvicultural treatments in a dipterocarp forest in Kalimantan, Indonesia: A mixed-effects modelling approach. Forest Ecology and Management 2017; 396: 195-206. http:// dx.doi.org/10.1016/j.foreco.2017.04.025.

Mori CLSO, Brito JO, Scolforo JRS, Vidal EJ, Mendes LM. Influence of altitude, age and diameter on yield and alpha-bisabolol content of candeia trees (Eremanthus erythropappus). Cerne 2009; 15(3): 339-345.

Nutto L. Manejo do crescimento diamétrico de Araucaria angustifolia (Bert.) O. Ktze. baseado na árvore individual. Ciência Florestal 2001; 11(2): 9-25.

Pérez JFM, Scolforo JRS, Oliveira AD, Mello JM, Borges LFR, Camolesi JF. Sistema de manejo para a candeia Eremanthus erythropappus (DC.) Macleish - a opção do sistema de corte seletivo. Cerne 2004; 10(2): 257-273.

R Development Core Team. R: A language and environment for statistical computing. Vienna: R Foundation for Statistical Computing; 2015.

Santos L, Oliveira M, Nogueira G, Pereira I, Silva M. Relative age and passage time for Eremanthus incanus (Less.) Less in a recovery area in the municipality of Diamantina-MG. Floresta e Ambiente 2016; 24: 1-10.

Scolforo JRS. Biometria Florestal: modelos de crescimento e produção florestal. Lavras: Editora UFLA; 2006.

Scolforo HF, Scolforo JRS, Mello JM, Ferraz AC Fo, Rossoni DF, Altoé TF et al. Autoregressive spatial analysis and individual tree modeling as strategies for the management of Eremanthus erythropappus. Journal of Forestry Research 2016a; 27(3): 595-603. http://dx.doi. org/10.1007/s11676-015-0185-y.

Scolforo JRS, Altoe TF, Scolforo HF, Mello JM, Silva CPC, Ferraz AC Fo. Management strategies of Eremanthus erythropappus (DC.) MacLeish under different initial spacing. Ciência e Agrotecnologia 2016b; 40(3): 298-304. 